\title{
Agalactosyl IgG in inflammatory bowel disease: correlation with C-reactive protein
}

\author{
R Dubé, G A W Rook, J Steele, R Brealey, R Dwek, T Rademacher, J Lennard-Jones
}

\begin{abstract}
The proportion of oligosaccharide chains on the Fc fragment of IgG which terminate with $\mathrm{N}$-acetylglucosamine (GlcNAc) rather than galactose is increased in rheumatoid arthritis and tuberculosis, and in sera from patients with Crohn's disease, probably because of decreased activity of a galactosyltransferase in B lymphocytes. We have assayed the prevalence of agalactosyl oligosaccharides on IgG in sera from 67 patients with inflammatory bowel disease (32 ulcerative colitis and 35 Crohn's disease). The prevalence of agalactosyl IgG significantly increases in the majority of Crohn's patients (19/35 patients), and correlates with the level of $\mathrm{C}$-reactive protein $(r=0.79)$, and inversely with the concentration of serum albumin. Sera from ulcerative colitis patients show less frequent (nine of 32) and less marked rises in agalactosyl IgG, and sera with high $\mathrm{C}$-reactive protein values can contain normal levels. Thus in ulcerative colitis no correlation was seen between the two assays. The diseases in which the percentage of agalactosyl IgG is raised (rheumatoid arthritis, tuberculosis, Crohn's disease and some ulcerative colitis) are characterised by simultaneous $\mathbf{T}$ cell mediated granulomatous tissue damage, and acute phase responses. Levels are normal in less tissue damaging granulomatous conditions, including sarcoidosis, and leprosy (except during episodes of erythema nodosum leprosum). We suggest therefore that a raised percentage of agalactosyl IgG is a correlate of a particular type of $T$ cell mediated pathology which may be relevant to the pathogenesis of inflammatory bowel disease.
\end{abstract}

The fact that immunoglobulins are glycoproteins is often ignored. It has become clear, however, that changes in the composition of the sugar components of immunoglobulins correlate with certain clinical states, and may have important functional significance. Thus there is a conserved N-glycosylation site on the Fc of IgG, at asparagine 297 on the $\mathrm{CH} 2$ domain. This site bears essentially non-sialylated $(90 \%)$ branched (biantennary) oligosaccharides, a variable proportion of which bear terminal galactose on one or both of their outer arms. When galactose is not present the terminal sugar is usually $\mathrm{N}$-acetylglucosamine (GlcNAc). In sera from normal donors the proportion of oligosaccharide chains bearing no terminal galactose (G0) decreases from a level of about $30 \%$ in small children to a trough of approximately $20 \%$ at the age of 25 years. Then it increases steadily with age to about $40 \%$ by 70 years.' In rheumatoid arthritis there is an increased prevalence of G0 (percent- age of agalactosyl IgG) which parallels the activity of the disease. ${ }^{23} \mathrm{~A}$ rise is also seen in tuberculosis and was found in a preliminary study of a small number of sera from patients with Crohn's disease. ${ }^{3}$ These increases are caused by changes in the activity of galactosyltransferase in B lymphocytes. ${ }^{+}$Diseases in which no changes in the percentage of agalactosyl IgG are seen include SLE (unless Sjögrens syndrome is also present), osteoarthritis, multiple sclerosis, Klebsiella infections, myositis, and a range of viral infections. ${ }^{3}$ Of particular interest is the absence of a raised percentage of agalactosyl IgG in two other granulomatous diseases, sarcoidosis and leprosy, ${ }^{3}$ though it rises in the latter during episodes of erythema nodosum leprosum. ${ }^{5}$ These disease associations suggest that the percentage of agalactosyl $\mathrm{IgG}$ rises when there is both chronic $\mathrm{T}$ cell-mediated pathology and an acute phase response.

We confirm here that the percentage of agalactosyl IgG rises in Crohn's disease, show that it also rises in a minority of patients with ulcerative colitis, and investigate its relationship to clinical and biochemical parameters in both diseases.

\section{Methods}

\section{PATIENTS}

Between January 1988 and November 1988 sera were collected from 67 patients ( 33 men, 34 women) who attended the outpatient clinic, or were admitted to the hospital because of exacerbation of their disease. Patients age $>60$ years were excluded. The group included 35 with Crohn's disease (16 men, 19 women) and 32 with ulcerative colitis ( 17 men, 15 women). The diagnosis in all cases had been established by standard clinical, radiological, and histopathological features.

\section{CLINICAL AND BIOCHEMICAL DATA} COLLECTED

At the time that serum was obtained for measurement of the percentage of agalactosyl IgG, the following tests were done: full blood count, ESR, C-reactive protein and liver function tests. Other acute phase proteins were measured in a subset of the Crohn's disease sera. Clinical activity of the disease was also assessed using a slightly modified Harvey-Bradshaw activity index (liquid stool frequency: less than 3,$0 ; 3$ to 5,1 ; more than 5,2 ).

MONOCLONAL ANTIBODY TO TERMINAL N-ACETYLGLUCOSAMINE (GICNAC)

The monoclonal antibody used for the immuno- \\ J Lennard-Jones \\ Correspondence to: \\ G A W Rook, Dept Medical \\ Microbiology, University \\ Microbiology, Univer \\ 10 July 1989
}


assay of agalactosyl IgG has been described elsewhere. ${ }^{6}$ Briefly, mice were immunised with group A streptococcal cell wall peptidoglycan/ polysaccharide complex, (as the group A polysaccharide bears much terminal GlcNAc), and monoclonals were selected for binding to fetuin treated with enzymes to remove sialic acid and galactose, (asialo-, agalacto- fetuin), resulting in exposed terminal GlcNAc. The antibodies were then further screened on agalactosyl IgG."

\section{STANDARDS FOR THE IMMUNOASSAY FOR} AGALACT OSYL Ig G

Serum and IgG samples of which the galactose values had been obtained by a previously published biochemical procedure were used as standards throughout this study. Briefly, the $\mathrm{N}$-linked oligosaccharides were released from the IgG using anhydrous hydrazine, and purified. The percentage of these oligosaccharides bearing no terminal galactose residues was then determined by measuring the hydrodynamic volume after exposure to an exoglycosidase mixture.' The set of standards used was derived from normal donors, tuberculosis, and rheumatoid arthritis patients.

\section{IMMUNOSSAY FOR AGALACTOSYL IgG}

Using a template and sharp scalpel, nitrocellulose sheets were shaped into 'combs' with 12 teeth, spaced so that each tooth could enter a microtitre well, while the backbone of the comb was supported on the sides of the wells. The entire combs were then incubated for two to three days in protein A (P-6031, Sigma) at $250 \mu \mathrm{g} / \mathrm{ml}$ in phosphate buffered saline. The protein A-coated nitrocellulose was then washed in $1 \% \mathrm{PBS} / \mathrm{BSA} / \mathrm{T}$ ween for two hours at room temperature.

Serum samples were diluted one in 50 in a buffer consisting of $0 \cdot 1 \mathrm{M}$ glycine and $0 \cdot 16 \mathrm{M}$ $\mathrm{NaCl}$ adjusted to $\mathrm{pH} 7 \cdot 0$ with $\mathrm{NaOH}$ to reduce aggregation of IgG. ${ }^{7}$ Aliquots of $0.25 \mathrm{ml}$ were placed in flat bottomed microtitre wells in triplicate. The protein A-coated combs of nitrocellulose were placed in these wells and incubated at room temperature for four hours with occasional agitation. Then the combs were removed from

TABLE I Characterisation of the patients studied

\begin{tabular}{|c|c|c|}
\hline & Crohn's disease $(n=35)$ & ulcerative colitis $(n=32)$ \\
\hline Age (Mean and range) & $34(16-59)$ & $38(20-60)$ \\
\hline History ( $\mathrm{yr}$ and range) & $6(1-30)$ & $5(1-29)$ \\
\hline \multicolumn{3}{|l|}{ Site of disease } \\
\hline Whole colon & 2 & 16 \\
\hline Rectum to midtransverse & 0 & 1 \\
\hline Left colon & 3 & 9 \\
\hline Rectosigmoid & 3 & 9 \\
\hline Ileocolonic & 9 & $\mathrm{NA}^{\star}{ }^{\star}$ \\
\hline Small bowel only & 8 & NA \\
\hline Ileostomy & 2 & NAt \\
\hline Ileocolonic anastomosis & 8 & NA $\ddagger$ \\
\hline \multicolumn{3}{|c|}{$\begin{array}{l}\text { Treatment (age corrected the percentage of } \\
\text { agalactosyl) })^{\prime \prime}\end{array}$} \\
\hline Prednisolone only & $16(17 \cdot 3(14 \cdot 8)) 5$ & $6(1.75(4.9)) 8$ \\
\hline 5-ASA/sulphasalazine only & $8(8 \cdot 7(12 \cdot 1))$ & $9(5.9(12 \cdot 6))$ \\
\hline Pred + 5-ASA/sulphsal & $4(14.9(11.8))$ & $13(9 \cdot 2(11 \cdot 5))$ \\
\hline Azathioprine \pm other drugs & $3(32(2 \cdot 6))$ & $4(3 \cdot 2(7 \cdot 2))$ \\
\hline No treatment & $4(8.5(6.1))$ & 0 \\
\hline
\end{tabular}

^Not applicable; †Colon resected; $\ddagger$ Terminal ileum resected; $₫$ Mean increase in percent agalactosyl IgG above the normal values for donors of the same age, in each treatment group (SD). the wells, washed twice in $1 \% \mathrm{BSA}, 0.05 \%$ Tween 20 in PBS (PBS/BSA/Tween), once in PBS, and fixed in $0.5 \%$ glutaraldehyde in PBS for $30 \mathrm{~min}$ at $0^{\circ} \mathrm{C}$. Fixed combs were washed again in $\mathrm{PBS}$ at $4^{\circ} \mathrm{C}$ containing $0 \cdot 1 \mathrm{M}$ lysine, then boiled for five minutes in PBS in a double waterbath to denature the IgG and expose the sugars.

The nitrocellulose was then incubated on a rocking platform at room temperature for three hours with biotinylated anti-GlcNAc GN7 at a dilution of $1 / 2000$ in PBS/BSA/Tween. After careful washing the nitrocellulose was incubated for two hours at room temperature in an avidin/ peroxidase complex (Amersham) diluted 1/500 in PBS/BSA/Tween.

Subsequently the binding of peroxidase was revealed with a conventional mixture of hydrogen peroxide and precipitating chromogen (4chloronaphthol, Sigma) in $5 \mathrm{mM}$ Tris $/ \mathrm{HCl}$ buffer at $\mathrm{pH} 7 \cdot 6$ for 15 minutes. After drying the tests were read with a transmitted light photometer adapted from a simple ELISA reader described previously.

CALCULATION OF RESULTS

A curve fitting program (Dataplot, by $S M$ Fraser, Strathclyde University, Glasgow, UK) was used to plot the absorbance values yielded by the standards in the immunoassay, against the percentage of agalactosyl IgG previously determined biochemically. A log linear correlation was found $(r=0.94)$. The same program was used to calculate correlations, and to interpolate values for the unknown sera from patients with ulcerative colitis and Crohn's disease. Repeat assays of unknown sera gave a mean variation of $(4 \cdot 7) \%$.

\section{Results}

\section{CHARACTERISATION OF THE PATIENTS} STUDIED

Details of the patients studied are shown in Table I. The Crohn's disease and ulcerative colitis groups were comparable in terms of age, sex ratio, duration of disease and disease activity (Harvey-Bradshaw index for Crohn's disease (mean (SD)) was $3.3(1 \cdot 7)$; for ulcerative colitis, $2 \cdot 97(1 \cdot 7))$

\section{AGALACTOSYL IgG}

Agalactosyl IgG was measured as described. The results are plotted against the age of the donor in Figures $1 a, b$, because of the known age variation discussed in the introduction. The Figure also shows the mean values for normal donors of the same age and two standard deviations either side of the mean. These normal values were taken from Parekh et al.' The percentage of agalactosyl IgG in sera from 19/35 patients with Crohn's disease fell well above $2 \times \mathrm{SD}$, whereas only nine of 32 ulcerative colitis samples did so (and four of these nine patients were borderline, Figure 1b). The difference between the diseases was significant, $(\mathrm{p}<0 \cdot 009$, Fisher's exact test) although the distribution of disease activity was similar. 


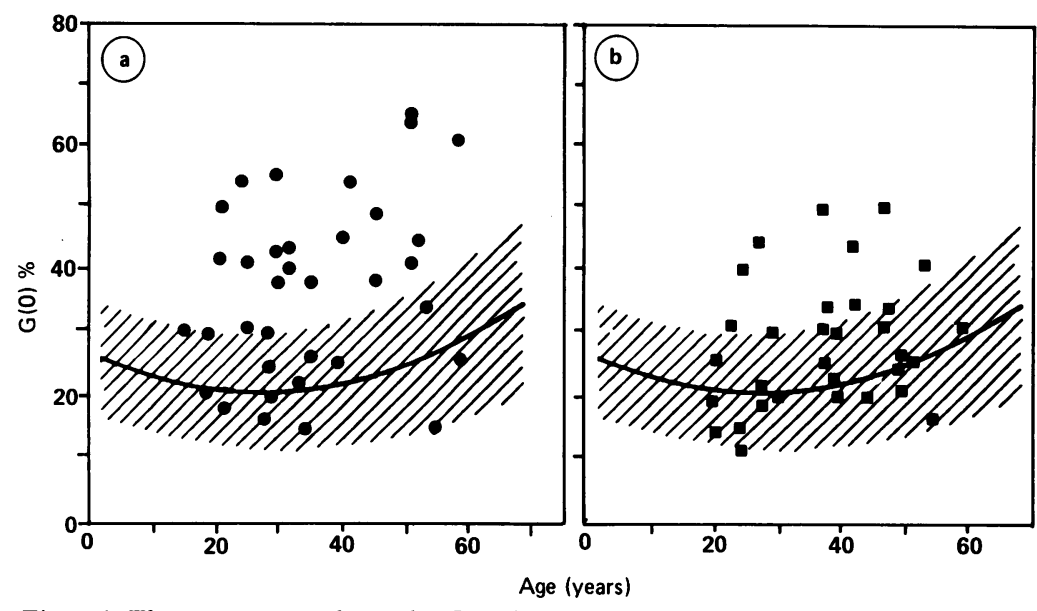

Figure 1: The percentage agalactosyl IgG(GO) for 35 patients with Crohn's disease (Fig la) and 32 patients with ulcerative colitis $(F i g ~ l b)$ plotted against the age of the donor. The black line indicates the mean percentage of agalactosyl for normal donors of the same age. The hatched area shows two standard deviations either side of that mean. Nineteen of 35 patients with Crohn's disease, and nine of 32 patients with ulcerative colitis fall outside the $2 \times S D$.

\section{CORRELATION BETWEEN PERCENTAGE}

AGALACTOSYL IgG AND OTHER

PARAMETERS OF DISEASE

Before seeking correlations with other clinical and biochemical parameters, each value was corrected for the age of the donor by subtracting the percentage of agalactosyl IgG anticipated in serum from normal donors of the same age (shown in Figure 1). The correlations sought are shown in Table II. In sera from Crohn's disease there were significant positive correlations between CRP $(\mathrm{r}=0.79 ; \mathrm{p}<0.005)$ and alpha-1acid glycoprotein $(r=0.69 ; \mathrm{p}<0.01)$, and a significant negative correlation with serum albumin $(\mathrm{r}=0.389 ; \mathrm{p}<0.05)$. (The latter is not secondary to liver damage as a separate study of 13 patients with cirrhosis severe enough to cause dysfibrinogenaemia has shown no abnormality of agalactosyl IgG concentrations.) There was no correlation with the Harvey-Bradshaw index in either disease. In ulcerative colitis, however, there was a. weak correlation $(r=0.42 ; p<0.05)$ between the rise in the percentage of agalactosyl IgG and the platelet count.

The correlation with C-reactive protein in Crohn's disease is shown in Figure 2. It can be seen that in sera from patients with undetectable $\mathrm{C}$-reactive protein (and inactive disease) the values for the percentage of agalactosyl IgG fall around zero as expected after subtraction of the relevant normal value. The mean for these patients $(\mathrm{SD})$ is $4.9(8 \cdot 3) \%$. This is close to zero, and the degree of scatter either side of zero is compatible with the degree of variation seen in normal sera (Fig 1).' As the C-reactive protein rises, however, so does the the percentage of agalactosyl IgG. Thus Crohn's disease patients with $\mathrm{C}$-reactive protein values of $>40$ always had a percentage of agalactosyl IgG which was

TABLE II Correlation between age-corrected increases in percent agalactosyl IgG and six clinical parameters

\begin{tabular}{llllllll}
\hline & Albumin & WBC & Platelets & ESR & Clin $S c^{\star}$ & CRP & $\alpha-1-A G P t$ \\
\hline CD & $-0.389 \ddagger$ & 0.106 & 0.25 & 0.335 & 0.199 & $0.79 \$$ & $0.69 \|$ \\
UC & -0.306 & 0.028 & $0.42 \ddagger$ & 0.204 & 0.306 & 0.164 & ND
\end{tabular}

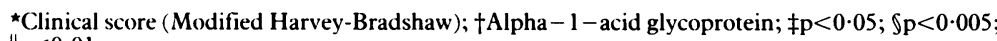
$\| \mathrm{p}<0 \cdot 01$. more than $2 \times \mathrm{SD}$ higher than the mean value found in sera from normal donors of the same age. In contrast, in ulcerative colitis sera, the percentage of agalactosyl IgG showed no correlation with C-reactive protein (Fig 3), which was high in some patients with a normal percentage of agalactosyl IgG. This difference between the two diseases was still apparent when only those Crohn's disease patients with colonic disease without ileal involvement were included in the calculation since these eight patients had a mean percentage of agalactosyl IgG 19\% (16.872) above the normal value, and four of eight fell more than $2 \times \mathrm{SD}$ above the normal value.

\section{Discussion}

The present data confirm that the percentage of agalactosyl IgG markedly rises in Crohn's disease, and show that this correlates with the rise in Creactive protein, and the fall in serum albumin in this disease. In contrast, there is no significant rise in the percentage of agalactosyl IgG in the majority of cases of ulcerative colitis, and when there is a rise it does not correlate with $\mathrm{C}$-reactive protein. Thus there are ulcerative colitis patients with striking levels of $\mathrm{C}$-reactive protein who have a normal percentage of agalactosyl IgG, a situation not seen in Crohn's disease. The clinical associations of raised percentage of agalactosyl IgG discussed in the introduction suggest that this glycosylation change occurs when there is $T$ cell-dependent granulomatous inflammation with tissue damage and an acute phase response. Thus it is significant that previous authors have noted that the nature of the acute phase response differs in the two diseases. ${ }^{9-11}$ During the acute phase response there are changes in the glycosylation of acute phase proteins secreted by the liver, and cytokines released from macrophages have been implicated in an in vitro system. ${ }^{12} \mathrm{We}$ speculate therefore that a cytokine released from macrophages activated by $\mathrm{T}$ cells may also be responsible for the down regulation of galactosyltransferase in B cells which is responsible for the change in glycosylation. ${ }^{*}$

Our previous observations on the clinical correlates of raised agalactosyl IgG, suggest that

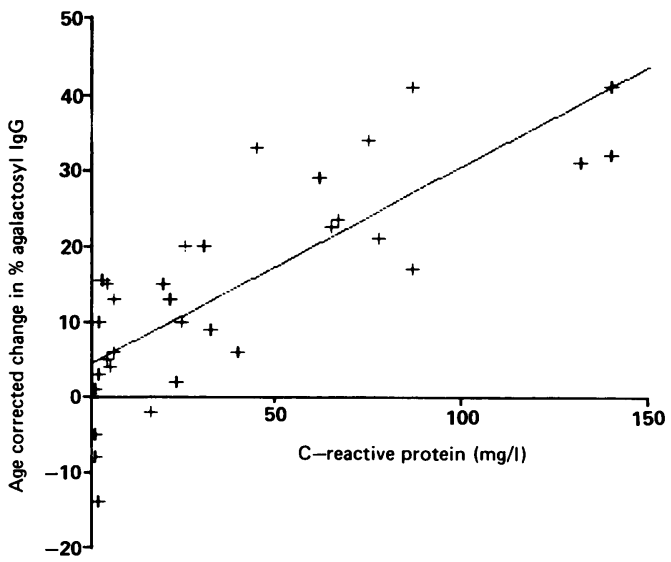

Figure 2: Correlation $(r=0 \cdot 79 ; p<0.005)$ between percentage agalactosyl IgG $(\% G O)$ and $C$-reactive protein in the sera of patients with Crohn's disease. In order to correct for variation in the percentage of $G 0$ due to age, 'the mean value of the percentage of $G 0$ for normal donors of the same age as each patient has been subtracted. 
Figure 3: Correlation between the percentage of agalactosyl IgG and Creactive protein in the sera of patients with ulcerative colitis. The data are calculated as for Figure 2. There is no significant relationship between the two assays.

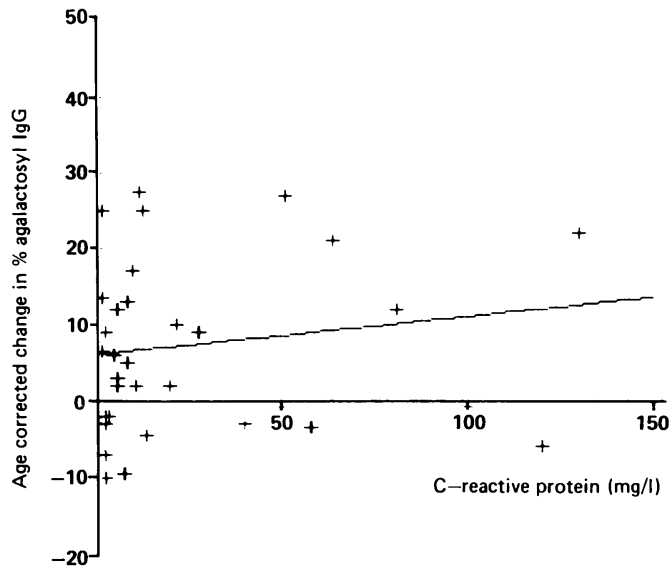

it rises when there is chronic $\mathrm{T}$ cell mediated inflammation leading to, or accompanied by, an acute phase response, but not when there is an acute phase response without such a $\mathrm{T}$ cell component. ${ }^{35131+}$ Thus the percentage of agalactosyl IgG rises in rheumatoid arthritis and tuburculosis, both of which are characterised by $\mathrm{T}$ cellmediated tissue damage and cytokine release. In rheumatoid arthritis there is release of cytokines such as IL-1, IL-6 and tumour necrosis factor into the joint, ${ }^{15}$ and circulation. ${ }^{16}$ These mediators are involved either directly or indirectly through release of IL- 6 , in the induction of the acute phase response. ${ }^{12}$ Similarly tuberculosis is accompanied by fever, weight loss, and necrosis in the lesions. This syndrome is readily explained by cytokine release ${ }^{17}$ triggered by the mycobacterial lipoarabinomannan. ${ }^{18}$ In contrast the percentage of agalactosyl IgG does not rise in sarcoidosis or uncomplicated leprosy where chronic $\mathrm{T}$ cell mediated granulomata are not accompanied by $\mathrm{T}$ cell mediated tissue damage (though there is damage secondary to nerve compression in leprosy) or a striking acute phase response. When there is an acute episode of $T$ cell mediated pathology and an acute phase response, as during erythema nodosum leprosum, the percentage of agalactosyl IgG rises even in leprosy. ${ }^{5}$

Moreover, because the percentage of agalactosyl IgG was not raised in sera from several acute virus infections, ${ }^{318}$ and we have recently found that it is not raised during acute rheumatic fever, ${ }^{19}$ and falls during pregnancy (Rook, Whyte et al, in preparation) it is likely that an acute phase reaction without chronic $\mathrm{T}$ cellmediated pathology does not lead to the formation of agalactosyl IgG. Thus the difference between Crohn's disease and ulcerative colitis noted in the present study could be related to the known difference in the nature of the acute phase response in the two diseases, ${ }^{9-11}$ or to differences in the nature of $\mathrm{T}$ cell function which are suggested by the greater prevalence of granuloma formation in Crohn's disease.

Finally, the occurrence of raised percentage of agalactosyl IgG in tuberculosis, rheumatoid arthritis, and Crohn's disease is provocative as one is a known mycobacterial disease, and these organisms, or autoantigens cross reactive with them, are implicated by some authors in the others. ${ }^{20} 21$

We are grateful to G D Searle Ltd for financial support

I Parekh RB, Isenberg DA, Roitt IM, Dwek RA, Rademache TW. Age-related galactosylation of N-linked oligosaccharides of human serum IgG. 7 Exp Med 1988; 167: 1731-6.

2 Parekh RB, Dwek RA, Sutton BJ, et al. Association of rheumatoid arthritis and primary osteoarthritis with changes in the glycosylation pattern of total serum IgG. Nature 1985; 316: $452-7$.

3 Rademacher TW, Parekh RB, Dwek R, Isenberg D, Rook GAW, Axford JS, Roitt I. The role of IgG glycoforms in the pathogenesis of rheumatoid arthritis. Springer Semin Immun opathol 1988; 10: 231-49.

4 Axford JS, Mackenzie L, Lydyard PM, Hay FC, Isenberg DA, Roitt IM. Decreased B cell galactosyl transferas in rheumatoid arthritis. Lancet 1987; ii: 1486-8.

5 Filley E, Andreoli A, Steele J, et al. A transient rise in agalactosyl IgG correlating with free IL-2 receptors during episodes of erythema nodosum leprosum. Clin Exp Immunol 1988; 76: 343-7.

6 Rook GAW, Steele J, Rademacher T. A monoclonal antibody raised by immunising mice with Group A streptococci binds raised by immunising mice with Group A streptococci binds 1988; 47: 247-50.

7 Hansson UB, Uesson M, Alkner U. Isolation and characterisation of intermediate complexes and other components with common antigenic determinants. Scand F Immunol 1981; 13 : $57-66$.

8 Rook GAW, Cameron HC. An inexpensive portable batteryoperated photometer for the reading of ELISA tests in microtitration plates. F Immunol Methods 1981; 40: 109-14.

9 Calvin J, Neale G, Fotherby KJ, Price CP. The relative merits of acute phase proteins in the recognition of inflammatory conditions. Ann Clin Biochem 1988; 25: 60-6.

10 Fagan EA, Dyck RF, Maton PN, et al. Serum levels of $\mathrm{C}$-reactive protein in Crohn's disease and ulcerative colitis. C-reactive protein in Crohn's dise
Eur f Clin Invest 1982; 12: 351-9.

11 Saverymuttu SH, Hodgson HJF, Chadwick VS, Pepys MB Differing acute phase responses in Crohn's disease and ulcerative colitis. Gut 1986;27: 809-13.

12 Mackiewicz A, Ganapathi MK, Schultz D, Kushner X. Monokines regulate glycosylation of acute-phase proteins. $\mathcal{J}$ Exp Med 1987; 166: 253-8.

13 Rook GAW. Mycobacteria, the glycosylation of IgG, and rheumatoid arthritis. Scand f Immunol 1988; 28: 487-93.

14 Parekh R, Isenberg D, Rook GAW, Roitt I, Dwek R, Rademacher $T$. A comparative analysis of disease associated changes in the glycosylation of serum IgG. F Autoimm 1989; 2: $101-14$.

15 Hopkins SJ, Meager A. Cytokines in synovial fluid: I. The presence of tumour necrosis factor and interferon. Clin Exp Immunol 1988; 73: 88-92.

16 Eastgate JA, Symons JA, Wood NC, Grinlington FM, di-Giovine FS, Duff GW. Correlation of Plasma Interleukin 1 levels with disease activity in rheumatoid arthritis. Lance 1988; ii: 706-9.

17 Rook GAW. The role of activated macrophages in the immun opathology of tuberculosis. Bri Med Bull 1988; 44: 611-23.

18 Moreno C, Taverne J, Mehlert A, et al. Lipoarabinomanna from Mycobacterium tuberculosis induces the production of tumour necrosis factor from human and murine macrophages. Clin Exp Immunol 1988; 76: 240-5.

19 Bahr GM, Yousof AM, Majeed HAM, et al. Agalactosyl IgG, antibodies to heat shock proteins, and acute rheumatic fever. antibodies to heat shock proteins, and

20 Gitnick G. Is Crohn's disease a mycobacterial disease after all? Dig Dis Sci 1984; 29: 1086-8.
Dick G. Is Crohn's disease a my

21 Rook GAW. Rheumatoid arthritis, mycobacterial antigens and agalactosyl IgG. Scand F Immunol 1988; 28: 487-93. 